\title{
ГЛОБАЛЬНОЕ ГРАЖДАНСКОЕ ОБЩЕСТВО КАК ЦИВИЛИЗАЦИОННЫЙ ОРИЕНТИР РОССИИ
}

\author{
Билалов М. И.
}

В статье прослеживается генезис современного гражданского общества. Анализируются особенности гражданского общества в свете концепичии модернизации и постсовременности, рассматривается роль европейских и азиатских иенностей в перспективах гражданского общества. Как ичивилизационный ориентир России и Дагестана обосновывается глобальное гражданское общество.

Ключевые слова: гражданское общество, глобальное гражданское общество, модернизация, постсовременность, ичивилизационный ориентир, Россия, Дагестан.

The genesis of modern civil society is traced in the article. The features of civil society are analyzed in the light of the concepts of modernization and postmodernity, the role of European and Asian values in the prospects of civil society is considered, a global civil society is being established as a civilizational guide of Russia and Dagestan.

Keywords: civil society, global civil society, modernization, postmodernity, civilizational guide, Russia, Dagestan.

Ни один философ не мог согласовать государственные принципы с моралью, и никто не сумел предложить принципы, которые не противоречили бы человеческой природе.

И. Канm

Преамбула. В современной политической практике России в целом реализуется искаженное представление о гражданском обществе. Большинство его адептов сориентированы на западные - европейские и североамериканские - классические гражданские общества, характерные для индустриальной эпохи. Порой и в теории (в глобалистике, политологии, социологии, философии) немало путаницы в определении особенностей современных гражданских обществ, связи государства, негосударственных структур и общественных объединений и т. п. Данные вопросы особо проблематизируются в эпоху глобализации, которая вносит в эти и без того запутанные общественные связи множество неясностей. Не могу не отметить вклад в прояснение соответствующих вопросов журнала «Век глобализации» с его весьма удачным и точным названием, его создателя и известного научного авторитета по многим этим вопросам профессора А. Н. Чумакова. Сошлюсь на некоторые его публикации последних лет только в этом журнале [см., например: Чумаков 2013; 2014a; 20146; 2015; 2016] и др., которые были методологически значимы в осмыслении вопросов данной статьи.

\footnotetext{
* Билалов Мустафа Исаевич - д. ф. н., профессор, заведующий кафедрой онтологии и теории познания Дагестанского государственного университета. E-mail: mibil@mail.ru.
}

Век глобализации 2/2018 126-139

DOI: $10.30884 / v g l o b / 2018.02 .10$ 
Гражданское общество в свете концепций модернизации и постсовременности. Особое значение для исследования перспектив гражданского общества имеют современные теоретические схемы, предлагаемые концепциями модернизации и постсовременности (А. Турен, Ю. Хабермас, Э. Гидденс, З. Бауман и др.). В них гражданское общество определяется либо как общество, приходящее на смену традиционному общественному укладу, либо как общество, вырастающее из современного состояния и несущее в себе все его черты. В обоих случаях речь идет не о различных типах общества, а всего лишь о разных фазах или стадиях существования и развития гражданского общества, а также тенденциях сближения и компромисса между основными моделями общественного развития. Представители теории постсовременности не отрицают сам факт существования гражданского общества как такового и перспективы его совершенствования. Они лишь подчеркивают значение постсовременной постмодернистской, постиндустриальной фазы его развития.

Модернизация признается большинством теоретиков этой концепции как процесс вторичный, как бы повторяющий, копирующий сделанный кем-то первоначальный ход. Таковым предстает для всего человечества Запад - он стал своеобразным катализатором, который развивался, следуя логике собственной жизни, а все остальные модернизировались вслед за ним, боясь оказаться в стратегическом проигрыше. Концепция модернизации исходит из того, что в реальном мире сосуществуют и взаимодействуют досовременные, современные и постсовременные социальные системы. Наиболее развитые в экономическом и культурном отношении страны Запада уже выходят на постсовременный уровень развития. Значительная часть стран, в том числе и Россия, находятся на современной стадии развития или на этапе перехода к ней. Так называемые развивающиеся страны относятся по данной типологии к переходным или традиционным формам общества, в которых гражданское общество находится еще в «эмбриональном» состоянии, хотя эти же развивающиеся страны ныне весьма проблематично зафиксировать в чистом виде; можно согласиться, что «постсовременность всех касается, мы все в ней прописаны», постмодерн - «сам дух постсовременности», а постмодернизм - «это “партия” постмодерна, его авангард» [Рубцов 2016].

Для концепций модернизации и постсовременности актуальны идеи коммуникативного сообщества, о котором в социальной философии еще в XX в. размышляли как о своеобразном идеале реального сохранения человечества. При этом немецкий философ Юрген Хабермас возлагает на эмпирико-аналитические науки обеспечение технического интереса этого общества - гарантировать успешный контроль за поступками людей, а на историко-герменевтические науки практического интереса, ориентированного на расширение возможностей их взаимопонимания. Идеалом коммуникативного общества представляется свободный консенсус - согласие в результате обычной или научной дискуссии. Для возможности такого свободного консенсуса, по Хабермасу, необходимо исходить из условия, что каждый, кто вступает в коммуникацию, совершая любые речевые акты, должен выдвигать универсальное притязание на значимость - ясность выражения, истинность высказывания, правдивость намерения и корректность норм. Результат такого коммуникативного действия - дискурс, представляющий собой идеальную языковую ситуацию, в которой любой участник имеет равную возможность высказаться и которая свободна от внутреннего и внешнего давления. 
Карл Отто Апель, соглашаясь с Хабермасом в его теории консенсуса, считает возможным стремление к идеальному коммуникативному сообществу только в условиях, свободных от общественного давления. Для этого общество должно создать всеобщий консенсус посредством всех разумно оправданных притязаний, которые выдвинуты Хабермасом.

Джон Роулз изучает экономические основы такого общества. Он рассматривает законы, по которым должны регулироваться в обществе взаимные права и свободы граждан и распределение благ между ними. Для этого он проводит мысленный эксперимент - исходит из первобытного состояния общества, в котором господствуют принципы беспристрастности и неведения, позволяющие стремиться к такому строению общества, в котором учитывались бы интересы всех. Это возможно, по его мнению, если каждый имеет равное право на всеобъемлющую систему одних и тех же основных свобод, а социальное неравенство допустимо и законно лишь тогда, когда обеспечивает блага для слабейших (принцип различий).

Идеи коммуникативного общества не чужды и политической философии Ханны Арендт, которая исходит из опирающейся на Аристотеля теории действия, при этом из трех основных видов деятельности: труда, отдыха и действия - последний предстает как политическое действие. Действие и речь образуют свободное от господства пространство, в котором люди вступают в отношения и договариваются. В таком обществе политическая власть способна к коммуникативному действию, несовместимому с насилием. Таков еще один вариант будущего коммуникативного общества, неизбежного в силу все большей значимости общения и коммуникации для человечества как его бытийных социальных феноменов.

Современная цивилизация не только подвела человечество к глобальной коммуникации и коммуникативному сообществу, но благодаря средствам массовой информации и информационным технологиям качественно преобразовала коммуникативные связи в сфере познания, морали, искусства, воспитания и т. п. В этой позитивной тенденции есть свои слабые стороны. Интенсификация коммуникативных отношений сопровождается и негативными явлениями преобладания информационно-цифровых измерений за счет потерь в содержательно-смысловом аспекте, ослабевает интерес к личным контактам и т. п. Возрастание количества и скорости обработки информации глобализирует современное коммуникативное пространство, которое заполняется наиболее простыми оценками, нормами, стереотипами поведения, игнорирующими традиционные ценности. Разрушению классической культуры способствует также Интернет, который фрагментирует культуру выхолащиванием глубинного смысла путем ее дробления на события, бесконечные интерпретации, приводя к потере уникальности текста, интереса к его авторству, вообще к чтению как коммуникативному процессу.

Дискурс и новая рациональность в развитии гражданского общества. Акцент на дискурсе как на результате коммуникативного действия, на некоей идеальной языковой ситуации, в которой ее участник предельно свободен от внутреннего и внешнего давления, выводит концепции модернизации и постсовременности на качественно иную субъектную организацию в познавательной культуре, увязывает эти концепции измененными субъект-объектными отношениями в современной науке. Становится очевидной тесная связь современных коммуникативных сообществ с типами рациональностей. Заметнее всего это у Ю. Хаберма- 
ca, который рассматривает прагматический, этический и моральный способы приложения практического разума для организации общественного устройства. Необходимость морального употребления практического разума перекликается с кантовским заявлением о «внутреннем моральном законе», заключенном в человеке, а гражданское общество мыслится как результат консенсуса, подчиняющегося не этически-прагматическому дискурсу, а только моральному. Моральным может считаться правильное поведение в противоположность неправильному, совершаемое на основе моральной свободы - способности человека делать выбор между правильным и неправильным, то есть истинным и неистинным. Коммуникативное действие претендует на всеобщность, универсальность; оно нормативно обоснованно, что и отличает его от иных видов дискурса, хотя гражданское общество может функционировать на всех этих дискурсах, выражающих собой разные типы рациональности. Прагматический дискурс сопряжен с классической рациональностью, с критериями целесообразности, выгоды, пользы - подтип этического дискурса (индивидуализм, коллективизм). Характерное для него индивидуальное формирование воли свидетельствует о соответствии прагматического дискурса с золотым правилом нравственности («не делайте другим того, чего не хотите себе»).

В выстраиваемой дискурсивной иерархии, оставив в стороне моральный дискурс как идеальную (по Ю. Хабермасу) модель для построения гражданского общества, акцентируем внимание на этическом дискурсе, в котором можно разглядеть исток или продолжение прагматического; этический дискурс мыслится Хабермасом как допускающий коммунитаризм, соответствующий ценностной рациональности и не преуменьшает значимость индивидуальных жизненных проектов. Гражданин, находящийся в идентификации с коллективом, с коллективным началом в обществе, сохраняет позитивную форму индивидуализма, что открывает перспективу новой, современной исторической форме гражданского общества в рамках коммунитарного типа. «Никто не может быть вполне свободным, пока не будут свободны все; никто не может быть вполне нравственным, пока не будут нравственны все; никто не может быть вполне счастливым, пока не будут счастливы все», - так лаконично выразил преимущества коммунитаризма один из идеологов либерализма и противник коммунизма английский философ и социолог Герберт Спенсер.

Несмотря на значимость концепций модернизации и постсовременности в современном толковании гражданского общества, общей чертой различных теорий постмодернизма является отказ от поиска системообразующих факторов институционализации гражданского общества. Для большинства из них характерен взгляд на формирование гражданского общества как во многом спонтанный и поливариантный процесс, обусловленный как объективными, так и субъективными факторами. Однако вместе с тем делается допущение, что современный облик гражданского общества определяется прежде всего причинами нематериального характера. Здесь также разделяется мнение о том, что если на этапе зарождения гражданского общества в его современном виде первостепенное значение имеет развитие промышленной индустрии и техники, то на этапе перехода к постсовременности преобладающим становится влияние культуры. Разумеется, эта культура должна восприниматься как постмодернистская или ее соответствующая проекция, как доминирующая в современную эпоху глобализации во многих продвинутых в развитии странах, а также определяющая общий вектор интегрированных культур- 
ных систем в большинстве стран мира. И потому, на наш взгляд, оценка общественного прогресса, в том числе гражданского общества как цивилизационной перспективы человечества, должна быть проанализирована с позиций постмодернистской познавательной культуры, где поиск и нахождение истины, адекватной социальной картины, имеют свою специфику.

Восток и Запад в перспективах гражданского общества. Осмысление глобального гражданского общества как цивилизационного ориентира России и Дагестана основано на сближении западной и восточной культур, точнее, на пересмотре кардинальных положений первой и пополнении ее духовными достоинствами второй. Разумеется, не только в сфере гражданского общества мы наблюдаем противоречия между Востоком и Западом, они пронизывают весь продвинутый политический мир и предстают как столкновение цивилизаций. Но для выявления специфики западного и восточного гражданского общества надо учесть, что противоположности Востока и Запада могут быть разбиты на множество пар по многим сферам человеческого бытия: чувство - разум, природа - общество, дух материя, мистика - аскеза, дао - логос, интуиция - научное знание, коллективизм - индивидуализм, деспотизм - демократия, общее - частное, пассивность активность, закрытость - открытость, созерцательность - деятельность, внутренняя сторона - внешняя сторона, культура - цивилизация, традиция - новация, асимметрия - симметрия, субъективное понимание - объективное понимание, пространственно-образный тип - вербальный тип, минимальное сообщение максимальное сообщение. Однако в осмыслении перспективных особенностей гражданского общества имеет место все же свое фундаментальное противоречие. Нам представляется, что исходным глубинным различием между тем, что называют «Запад» и «Восток», является базисная ориентация принципов социального устройства либо на индивида, либо на некое общественное целое, на систему (будь то племя, община, империя или др.). Соответственно, эти два базисных культурных типа названы в науке персоноцентризмом и системоцентризмом.

В персоноцентристской шкале главное - индивид, все рассматривается через призму человеческой личности, приоритета в обществе ее прав и свобод. В системоцентристской же шкале ценностей индивидуальный человек либо вообще отсутствует, либо воспринимается как орудие или строительный материал для достижения каких-либо надындивидуальных - «системных» - целей, среди которых всегда были стабильность, неизменность социального порядка, а также, по возможности, экспансия, расширение зоны влияния. Но так было, так есть. Такая шкала ценностей вовсе не унижает личность, она может строиться на вполне нравственной основе. «Истинно честный человек должен предпочитать себе семейство, семейству - отечество, отечеству - человечество» - разве кто-нибудь возразит изречению французского ученого-энциклопедиста Жана Даламбера? Но системоцентризм допускает современные проявления корпоративного и коммунитарного типов гражданского общества, в котором, по Хабермасу, при доминировании коллективного начала возможно сокращение и позитивной формы индивидуализма. Тот этический дискурс немецкого философа может стать основой новой демократии для сближения Востока с Западом. И вот когда справедливо настаивают на том, «что гражданское общество и демократия - две стороны одной медали, которые друг без друга не существуют», что «в гражданском обществе и возможна демократия» [Чумаков 2016: 9], я бы уточнил: демократия эта в условиях России (да и всего остального мира) не должна носить характер сугубо либераль- 
ный, от нее и Запад отказывается. Безуспешные попытки построения либеральнодемократического классического гражданского общества лишь вызывают массовые симпатии к политическому авторитаризму. А вот вполне приемлемый и для Запада, и для Востока этический дискурс - основа другой, более эффективной для современности демократии.

Какая демократия оптимальна для современного гражданского общества? Восточные страны многие последние века и копируют, и заимствуют европейские ценности. Но эпоха глобализации встревожила Восток агрессивным вторжением в его глубинный духовный мир идеалов европейского Просвещения, целевого рационализма, что имело разрушительные последствия для этого мира, да и для самого современного Запада с целым рядом глобальных проблем. Так и с либеральной демократией, которую с подачи США склонны абсолютизировать и в ряде стран Западной Европы, и с навязываемыми мусульманским странам американскими нормами. Ныне от подобной навязчивости неудобно даже самим адептам этой демократии. Примечательны в этой связи очень интересные рассуждения Ю. Латыниной, которую не заподозришь в антипатии к Западу и европейским политическим системам. По ее мнению, обосновываемому многочисленными фактами политической жизни ряда стран всех континентов в трех номерах «Новой газеты», «Европа стала на путь промышленной революции не при демократии» [Латынина 2014, ч. 1], введение всеобщего избирательного права завершилось господством тирана и тоталитаризмом... Автор, на наш взгляд, неявно следует за глубокой мыслью Платона, заявившего в свое время: «Тирания возникает, конечно, не из какого иного строя, как из демократии; иначе говоря, из крайней свободы возникает величайшее и жесточайшее рабство» [Платон. Государство VIII, 564]. При всех возможных преувеличениях и конкретно-исторических преломлениях тезиса его смысл для нас очевиден. Этот смысл выражает афоризм апологета классического гражданского общества Карла Поппера: «Свобода, если она не ограничена, аннулирует самое себя».

Автор упомянутой статьи также убедительно показывает: одна из аксиом либерального дискурса, которая гласит, что «развитие рынка сопровождалось развитием демократии», мало соответствует действительности, а «демократия неразрывно связана с рынком» - попросту не выдерживает проверки фактами. По мнению Ю. Латыниной, «в основе современного дискурса о демократии лежит фундаментальная ложь: этот дискурс по умолчанию представляет дело так, что те ценности, которые сделали Европу Европой - неприкосновенность частной собственности, технический прогресс, наука, - все они каким-то образом исходили из “традиций европейской демократии”» [Латынина 2014, ч. 3]. Здесь уместно добавить, что совершенно справедливы сомнения в исключительной значимости рыночной экономики для демократии и всего современного гражданского общества.

Если коснуться ценностей демократии, то последовательный и обстоятельный анализ здесь выявляет, что сегодня в цивилизованном мире сталкиваются две стратегии. Как пишет В. Федотова в своем фундаментальном исследовании гражданских обществ Запада, имеет место, с одной стороны, стремление «насытить права человека локальными и региональными особенностями, приспособить их к наличному человеческому материалу», что ведет к противостоянию с универсальной природой прав человека, «К их национализации и приватизации», с другой попытка «приспособить данный человеческий материал к правам человека» [Фе- 
дотова 2005], то есть, как мы понимаем, абсолютизировать индивидуализм при очевидном его кризисе на Западе. Но сожалеть о том, что в том же Дагестане, да и в других регионах России, так и не созрели условия для предпочтительной долгое время в развитых странах второй стратегии, было бы неверно. Ведь на самом Западе, как мы сказали выше, наметился поворот к коммунитаристским и социалистическим ценностям. Да, преобладающее в регионе стремление к национальной консолидации принадлежащих к различным языковым группам, религиозным направлениям, этническим ментальностям и прочему народностей Дагестана, Северного Кавказа, других национальных регионов России входит в противоречие с современным (но уходящим в историю) состоянием прав человека на Западе [Проблемы... 2016]. Современные реалии таковы, что мы вынуждены подчинить наши демократические преобразования в первую очередь развитию этнокультурного плюрализма, соблюдению этнического паритета, принципа равной значимости и поддержки культуры всех этносов, что находит поддержку в перспективах постмодернистской культуры.

Петербуржский философ Б. Марков отмечает несостоятельность либеральной интерпретации права - она заключается в опоре на индивидуальный дискурс, в попытке «выпячиванием» неполитических ценностей человека ограничить влияние власти. Коммунитаризм опирается на своеобразный системный дискурс, где доминирует идея солидарности, изначального обеспечения общественной гармонии [см. об этом: Марков 2001]. Исходя из данного преимущества коммунитаризма и солидарности, разумно полагать, что ориентиром российских народов должно быть гражданское общество нового формата - общество экономики знаний и высоких технологий, умелого сочетания коммунитаристского подхода в экономике, культуре в противовес абсолютизации западной либеральной традиции, многопартийности непрозападных партий с реальными политическими платформами, мировоззренческого плюрализма с мощной общественной идеологией, основанной на отечественных ценностях... Тогда мы не расколем страну на Европу и Азию, на христианство и мусульманство, демократов и консерваторов - на этот курс народ пойдет в единстве.

Систематизируя общее в гражданских обществах всех стран и особенное для Запада и Востока, можно предложить следующую таблицу.

\begin{tabular}{|l|l|}
\hline \multicolumn{3}{|c|}{ Общее в гражданском обществе всех стран } \\
\hline • Правовое государство \\
• Демократическое устройство \\
• Плюрализм форм собственности \\
• Развитые НКО и другие негосударственные институты гражданского об- \\
щества \\
$\ldots$
\end{tabular}


Окончание табл.

\begin{tabular}{|l|l|}
\hline \multicolumn{2}{|c|}{\begin{tabular}{c}
\multicolumn{2}{|c|}{ Особенное в гражданском обществе } \\
дапод
\end{tabular}} \\
\hline \multicolumn{1}{|c|}{ Запейской и восточной цивилизаций } \\
\hline $\begin{array}{l}\text { Приоритет материального над духов- } \\
\text { ным }\end{array}$ & Приоритет духовного над материальным \\
\hline Эксплуатация природы & Гармония с природой \\
\hline $\begin{array}{l}\text { Доминирование частной собствен- } \\
\text { ности }\end{array}$ & $\begin{array}{l}\text { Доминирование государственной и об- } \\
\text { щественной собственности }\end{array}$ \\
\hline Либеральная демократия & Консоциональная демократия \\
\hline Президентская форма правления & $\begin{array}{l}\text { Сочетание двух основных видов респуб- } \\
\text { лики - президентской и парламентской } \\
\text { (при ведущей роли парламентской рес- } \\
\text { публики) }\end{array}$ \\
\hline Абсолютизация выборной системы & $\begin{array}{l}\text { Сочетание выборной системы с сильной } \\
\text { вертикалью власти }\end{array}$ \\
\hline Мультикультурализм & Политика культурной свободы \\
\hline$\ldots$ & $\ldots$ \\
\hline
\end{tabular}

Способно ли человечество к цивилизационному выбору? Однако не все пары противоположностей в приведенных выше перечне и таблице актуально значимы в глобализационном диалоге и полилоге культур и этносов, на первый план выдвигаются ценности общественно-политического устройства мира, хотя именно в попытке сближения всех этих полярных позиций человечество приближается к принципиально новому социуму. Наука еще не определилась со смыслом истории и целями человечества - эти вопросы не имеют однозначных ответов. С одной стороны, тот факт, что ключевые вопросы обществознания касаются всех людей, сообществ, стран и континентов, уже свидетельствует о единстве мира, человечества как социума, с другой - противоречия прогресса, разновекторность его направлений свидетельствуют о неочевидности этого единства. Поиск ответов лишь подтверждает это. Несмотря на расовое и этническое многообразие, на различия в исторических судьбах и уровнях экономического развития, географические и демографические условия бытия, все народы имеют общие потребности и интересы - в еде, жилье, образовании, медицинском обслуживании и т. п. и удовлетворяют их одинаковыми или сходными средствами и способами. Орудия производства, трудовые навыки, виды преобразуемой энергии, формы устройства семейно-бытовых отношений, способы получения знаний и их реализация на практике и т. п. в общих чертах совпадают, имея лишь некоторые различия. Человечество как постепенно складывающаяся общность людей есть продукт существования многих форм и способов человеческой деятельности, и эти корни прошлого определяют наше настоящее и будущее.

Человечество как сообщество когда-либо живших, ныне живущих и будущих людей объединяют в единый социум объективные, необходимые, устойчивые экономические и политические законы и тенденции, нравственные и религиозные принципы, наука и техника и т. п. Единство и целостность мира не означают обязательное устранение различий и стремление к единообразию, наоборот, предпо- 
лагают сохранение и приумножение самобытности народов, их обычаев и традиций, оригинального материального созидания и духовного творчества - всего того, что делает человеческий мир полнокровным, соответствующим природному и космическому разнообразию, адаптированным к многовариантному, неоднозначному ходу истории. Целостность современного мира не предполагает также американизации или европеизации глобализирующегося мира. Нельзя форсировать, искусственно ускорять стирание биологических, экономических, религиозных, культурных различий цивилизаций, наоборот, необходимо сохранить их специфический потенциал и установить между ними плодотворный диалог. Более того, если глобализация, идеологией которой является неолиберализм, будет продолжаться длительное время, то нельзя исключить апокалипсис.

Есть ли выход из нынешнего крайне критического положения? Есть. Следует отказаться от насильственной (субъективной) глобализации и вернуться к интернационализации, то есть к объективной логике истории [Гобозов 2017: 75]. Надо полагать, что футурологические дискуссии конца XX и начала XXI в. об однополярном или многополярном мире, борьбе и грядущем столкновении цивилизаций свидетельствуют о реальных противоречивых перспективах человечества в XXI в., в развертывании его единой мировой истории. И если здесь есть некий единый ориентир, то почему бы не учесть также афористическую точку зрения всемирно признанного футуролога Арнольда Тойнби: «Моя надежда на двадцать первый век в том, что он увидит установление глобального гуманистического общества, которое будет социалистическим на экономическом уровне и свободомыслящим на духовном уровне» (Тойнби 2006: 8).

Что такое глобальное гражданское общество? Несколько подробнее скажем о глобальном гражданском обществе как возможной единой перспективе человечества. Это предельно широкое внеполитическое сообщество людей, объединяющее в себе ряд однотипных в социально-политическом отношении социетальных общностей на основе единых ценностей и с целью решения общезначимых проблем всего человечества. Важной чертой этих сообществ является преодоление людьми границ институтов классического гражданского общества, включенность граждан тех или иных стран в международные структуры, имеющие большей частью протестный характер. Вот некоторые черты глобального гражданского общества, по мнению ученых-глобалистов. Во-первых, они подчеркивают растущую социальную ответственность частного бизнеса в этом обществе, предостерегая в то же время от опасности чрезмерной концентрации экономической власти и мощи в частных руках. Во-вторых, технологической основой глобального гражданского общества является развитие новейших технических средств коммуникации, обеспечивающих распространение глобальных потоков информации далеко за пределы государственных границ, что приводит к глобальной революции в общении. Третьей отличительной чертой глобального гражданского общества ученыеглобалисты считают формирование новой модели государства, уже не просто правового и социального, но и «социоприродного», «экологического», «устойчивого».

В чем, кроме вышеотмеченного в литературе, мы усматриваем специфические преимущества нового типа гражданского общества? Отвечая новым коммуникативным отношениям современного информационного общества, глобальное гражданское общество может приспособиться к различным дискурсам, выражающим собой разные типы рациональности. Оптимальный и наиболее эффективный в разрешении современных этнических, расовых и религиозных противоре- 
чий этический дискурс детерминирует корпоративные и коммунитарные типы гражданского общества, в котором при доминировании коллективного начала возможно сокращение и позитивной формы индивидуализма. Этот этический дискурс - основа также приемлемой для Востока и Запада демократии.

Дагестан в глобальном гражданском обществе. В свете вышеуказанного, сохраняя стратегический ориентир России на постиндустриальную цивилизацию в форме гражданского общества, мы считаем необходимым скорректировать этот курс страны с учетом тех изменений, которые претерпели гражданские общества классического (либерально-демократического) типа в движении к своему нынешнему состоянию в странах Запада. В чем эта коррекция могла бы выразиться в отношении наиболее проблемных регионов России, скажем, Дагестана? Выделим некоторые позиции в методологии (стратегии) движения к глобальному гражданскому обществу применительно к мусульманским республикам Северного Кавказа. Как известно, ядро этой методологии - цивилизационный подход, на первый план как особо значимый фактор и детерминант общественного развития, отодвинув на второй план способ производства и экономику, выдвигает культуру, ментальные и религиозные слагаемые духовного бытия народов. Надо учесть также и то, что наиболее развитые в экономическом и культурном отношении страны Запада уже выходят на постсовременный уровень развития, а значительная часть стран мира, в том числе и Россия, находятся на современной стадии развития или на этапе перехода к ней. А у Дагестана своя особенность - здесь сосуществуют досовременные, современные и постсовременные социальные системы, происходит своеобразная конвергенция модерна и постмодерна, значима роль ислама, в Дагестане гражданское общество находится еще в зачаточном состоянии и т. п.

В связи с цивилизационным ориентиром Дагестана особый разговор о роли религии в эпоху глобализации. Кстати, эта тема актуальна и в связи с будущим Запада. «На Западе идея возрождения религиозных корней культуры становится актуальной в 1970-е гг. - вместе с появлением неоконсерватизма и постмодернизма» [Силичев 2017: 143]. Позднее, как известно, она все больше набирает силу. Однако, по мнению Д. Силичева, «у России имеется гораздо больше оснований надеяться на возрождение религиозного начала в своей культуре» [Там же]. При этом в работе автора ссылки идут на Л. Карсавина, подчеркнувшего присущие русскому человеку «ощущения святости» и «нужность абсолютного», и на убедительные размышления Н. Бердяева, перенесшего идеалы христианского гуманизма и в коммунистический период жизни русского народа...

Эту превращенность формы религии, придание политическому порядку квазирелигиозного измерения в попытках наделить в рамках «политической религии» события современного мира сакрально-космическим характером подчеркивает А. В. Митрофанова. Она особо выделяет характерное для мусульманского мира придание религиозно-политическими движениями своим целям значимости главной задачи человечества, санкционированной самим Богом. На этом основании «политизированная религия представляет собой идеологию, позволяющую приложить религию к политике», - так появляются «исламизм», «православизм» и, по мнению зарубежных исследователей, «“этот феномен является «измом», сравнимым с другими идеологиями двадцатого века" - то есть с марксизмомленинизмом и фашизмом» [Митрофанова 2008: 116-119]. 
Не считаю, что в духовной жизни Дагестана имеет место или значима политическая религия, тем более в идеологизированных формах «измов». Но сложное общественно-политическое напряжение последних десятилетий подвело Дагестан к необходимости серьезного исламского просвещения и образования, призванных перевести религиозную умму от невежественного состояния к просвещенному, что, конечно же, не означает достижения «единственно истинного» ислама. Однако традиционный для Северного Кавказа суфизм в гораздо большей степени демонстрирует содержательное богатство как теоретико-познавательных идей, так и морально-нравственных постулатов, уместных в условиях движения к гражданскому обществу. Мы неоднократно подчеркивали достоинства суфизма в сопоставлении с положениями ортодоксального ислама в мировоззренческой широте и синкретичности, аллегоричности и метафоричности утверждений, позволяющих отойти от агрессивной категоричности [см.: Билалов 2003; 2011; 2012; 2015]. Для Дагестана, стремящегося в прогрессивное сообщество народов, толерантность есть то измерение сознания, которое неотъемлемо от субъектных его составляющих (язык, культура, социальный статус, воля, мистический опыт, свобода, рассудок, разум, ответственность, символизация, воображение и т. п.), позволяющих постичь истину ислама, пронести и сохранить мусульманину его дух и жить в современном едином цивилизованном мире.

Актуальный для Дагестана тезис о зависимости формирования гражданского общества от культуры должен быть дополнен идеей культурного многообразия: каждая цивилизация, несмотря на универсализирующее влияние глобализации, относительно автономна и реализует заложенный в ней культурный потенциал в различных областях. Индикатором этого потенциала предстает отказ от стереотипов традиционного общества и движение в сторону культурного плюрализма, характерного для постмодерна и отражающего этническое многообразие республики.

Приемлемые модели глобального гражданского общества для России. Устремление человечества к принципиально новому социуму - глобальному гражданскому обществу - предполагает поиск его оптимальных моделей. Иначе говоря, в реалиях России и ее регионов к этой методологии должен быть подобран конкретный механизм движения к региональному варианту глобального гражданского общества. На наш взгляд, актуален подход современных отечественных исследователей гражданского общества А. Л. Нездюрова и А. Ю. Сунгурова [см.: Общество... 2005]. Они рассматривают в качестве ключевого для гражданского общества вопрос взаимосвязи государства и негосударственных институтов российского общества и предлагают три варианта взаимодействия органов власти и гражданских структур (сотрудничество, отсутствие сотрудничества [игнорирование] и конфронтацию), выделяя при этом конкретные исторические модели.

Из восьми моделей большинство (пять) в той или иной степени связаны с активной ролью государства в формировании гражданского общества. В их числе в России имеет место модель поддержки развития некоммерческих организаций (НКО), или «модель садовника», когда органы как федеральной, так и региональной власти принимают нормативные акты и действия, способствующие появлению и развитию независимых общественных организаций как основы зарождающегося гражданского общества, но и партнерская модель, когда государственные органы признают независимые неправительственные организации и не пытаются ими управлять, а участвуют в диалоге с НКО. Можно говорить о наличии и патер- 
налистской модели, когда государство оказывает поддержку деятельности неправительственных организаций (НПО) в виде предоставления бесплатных помещений или льготной аренды, прямого финансирования, преференций при распределении грантов и тому подобного при условии, что последние не вмешиваются в дела власти, а также обеспечивают поддержку соответствующих кандидатов на выборах. В обмен на политическую лояльность властные структуры разрешают определенную автономию неправительственных организаций.

Указанные авторы отмечают и имевшую место в СССР модель «приводных ремней», когда партийно-государственный аппарат рассматривал все общественные организации, находящиеся под полным контролем руководства партии, исключительно как передаточные механизмы воли КПСС к рядовым жителям страны.

Но возможны и варианты, которые, впрочем, нехарактерны для отечественной истории взаимоотношений власти и негосударственных структур. Скажем, модель игнорирования, когда государство не замечает большинства НКО, не мешает, но и не помогает их деятельности. Нежелательной моделью выступает модель борьбы с противником. Представители государства рассматривают независимые неправительственные организации как образования, представляющие опасность для их власти, и стараются осложнить деятельность таких организаций или даже закрывать их. Неприемлемыми являются взаимоотношения госорганов и общественных организаций, переходящие в плоскость политической борьбы. Это модель гражданского неповиновения. Она характерна для авторитарного или тоталитарного общества, когда нарушения властью гражданских прав человека и политических свобод вынуждают общественные организации избирать тактику участия в несанкционированных митингах, пикетах, других действиях, вызывающих репрессивный ответ власти.

Таким образом, можно заключить, что при всем многообразии моделей взаимоотношения государства и негосударственных структур в реальном становлении современного гражданского общества в России возможны различные фактические сочетания при соблюдении стратегии цивилизационного развития. Нужно принять во внимание, во-первых, то, что классическое гражданское общество как определенная стадия западной цивилизации переживает глубокий кризис и не должно быть ориентиром России, во-вторых, процесс становления гражданского общества в нашей стране затруднен из-за ориентиров на западные либерально-демократические гражданские общества классического типа, которые не подходят нашим народам из-за особенностей менталитета, традиционного материального и духовного уклада. В-третьих, вместе с цивилизованным миром Россия должна ориентироваться на глобальное гражданское общество, отличающееся от классического в первую очередь новым рационализмом и коммунитаризмом. В-четвертых, грядущая постмодернистская культура и глобализация с ее иррационализацией создают благоприятные перспективы для вхождения России и ее регионов в глобальное гражданское общество.

На наш взгляд, необходимо политически закрепить курс Дагестана на постиндустриальную цивилизацию в составе России как единого многонационального социума в форме гражданского общества с региональными базовыми ценностями. Этому курсу нужно придать статус национальной идеи дагестанских народов. Интегрируясь в глобальное гражданское общество, наши народы наконец-то обретут 
общие с «продвинутыми» нациями цели и ориентиры исторического развития [более подробно об этом см.: Билалов 2009]. Такой подход будет ответом на метафизический вызов времени - необходимость «создания ценностного горизонта для модернизации бытия - создание нации, способной жить в современности» [Столяров 2013]. И Дагестан, и Россия в целом должны достойно ответить на этот вызов.

Данной статье я предпослал эпиграф великого Иммануила Канта (к которому, кстати, отсылают многие теоретики глобального гражданского общества), одного из прозорливых провидцев будущего задолго до выработки каких-либо принципов современной футурологии. Этот афоризм при всей категоричности и определенной пессимистичности тем не менее указывает путь исследования цивилизационного ориентира человечества.

\section{Лuтература}

Билалов М. И. Гносеологические идеи в структуре религиозного сознания. М. : Academia, 2003.

Билалов М. И. Россия в глобальном гражданском обществе // Материалы Международного научного конгресса «Глобалистика-2009: пути выхода из глобального кризиса и модели нового мироустройства», Москва, МГУ имени М. В. Ломоносова, 2023 мая 2009 г.: в 2 т. / под ред. И. И. Абылгазиева, И. В. Ильина. Т. 1. М. : МАКС Пресc, 2009.

Билалов М. И. Гносеологические идеи в религиозном сознании // Вопросы философии. 2011. № 8. С. 177-180.

Билалов М. И. Влияние ислама и суфизма на познавательную культуру // Исламоведение. 2012. № 3. С. 23-34.

Билалов М. И. Онтологические и гносеологические различия суфизма и салафизма // Исламоведение. 2015. Т. 1(23). С. 61-68.

Гобозов И. А. Неолиберализм и глобализация // Век глобализации. 2017. № 2(22). C. 66-76.

Латынина Ю. Почему я не демократ. Манифест разочарованного интеллигента // Новая газета. 2014. 30 июля. № 83; 2014. 1 августа. № 84; 2014. 4 августа. № 85.

Марков Б. М. В поисках другого / Ю. Хабермас // Вовлечение другого. Очерки политической теории. М. : Наука, 2001.

Митрофанова А. В. Религиозный фактор в мировой политике // Век глобализации. 2008. № 1. C. 109-119.

Общество и власть: пути взаимодействия. Межрегиональное исследование / под ред. Г. Л. Бардиер, А. Ю. Сунгурова. СПб. : Норма, 2005.

Проблемы языка в глобальном мире: монография / под ред. Е. В. Ганиной, А. Н. Чумакова. М. : Проспект, 2016.

Рубцов А. Дух постмодерна и тупики постмодернизма // Новая газета. 2016. 16 марта. № 27.

Силичев Д. А. Культурное наследие и культурная политика постсоветской России // Культура в условиях глобализации. Взгляд из России: монография / под ред. А. Н. Чумакова. М. : КНОРУС, 2017. С. 135-163. 
Столяров А. Метафизический вызов. Какой должна быть национальная идея России? // Новая газета. 2013. 20 марта. № 30.

Тойнби А. Исследование истории: в 3 т. Т. 1. СПб. : Изд-во СПбГУ, 2006.

Федотова В. Г. Хорошее общество. М., 2005.

Чумаков А. Н. Еще раз о гражданском обществе // Вестник РФО. 2009. № 1.

Чумаков А. Н. Теоретико-методологические основания исследований процессов глобализации // Век глобализации. 2013. № 2(12). С. 23-37.

Чумаков А. Н. «Мягкая сила» как способ решения проблем в глобальном мире // Век глобализации. 2014a. № 2. С. 192-195.

Чумаков А. Н. О глобализации с объективной точки зрения // Век глобализации. 2014б. № 2. C. 39-51.

Чумаков А. Н. Культурно-цивилизационные разломы глобального мира // Век глобализации. 2015. № 2. С. 35-47.

Чумаков А. Н. Триосфера, эпометаморфоз и новые задачи глобалистики // Век глобализации. 2016. № 3. С. 3-15. 